\title{
EVACUATING ORANGE COUNTY, CALIFORNIA, IN ABOUT ELEVEN (11) SECONDS
}

\author{
J. Riechel ${ }^{\mathrm{a}, *}$ \\ ${ }^{\mathrm{a}}$ Center for Information Systems \& Technology (CISAT), Claremont Graduate University (CGU), Claremont, CA 91711, USA, \\ james.riechel@cgu.edu
}

KEY WORDS: Vehicle Evacuation Planning by Waypoints, Approximate Driving Distance

\begin{abstract}
:
Orange County, California, residents must evacuate when there is a crisis at the San Onofre nuclear power plant in San Clemente, California. They must travel roughly north and east over safe roads. Depending on their location in Orange County (OC), residents will travel to the closest of four (4) waypoints located on the border between OC and neighboring counties. Once a waypoint is reached, evacuees can travel in any direction except back toward OC. The approximate driving distance algorithm is used to suggest a possible waypoint for each address - business or residential. The approximate driving distance algorithm makes this evacuation planning possible, as it takes only around eleven (11) seconds on a state-of-the-art laptop to route 1.1 to 1.2 million addresses to waypoints. Using actual driving distances would take too long and be too expensive, taking approximately fifty-three (53) days on the same platform. The waypoint suggestions are just that: suggestions. In some cases, the approximate driving distance algorithm might not choose the closest waypoint.
\end{abstract}

\section{INTRODUCTION/LITERATURE REVIEW}

First, you need to know what population(s) to evacuate. In this work, it is assumed that the entire (business and residential) County of Orange, California, needs to be evacuated. Yet this may not be the case. In Yanovskiy et al. (2020), it is determined that "[b]ased on the performed analysis, we suggest avoiding evacuation if the projected first-year dose is below $500 \mathrm{mSv}$." One (1) millisievert ( $\mathrm{mSv}$ ) is the average amount of background radiation an individual will absorb in one (1) year. They base their analysis on data from the Fukushima Daiichi nuclear disaster in Japan.

"After the accidents of nuclear power plants at Chernobyl and at Fukushima, huge amounts of radioactive iodine were released into the atmosphere" (Ory et al., 2020). Of the two million children who lived close to Chernobyl, 7,000 cases of thyroid cancer were diagnosed in 2005. Further study is required to determine if these numbers are significant, as thyroid cancer is a very common disease. Yoshimura et al. (2020) report that there were significant differences between the types and amounts of radiation exposure at Chernobyl and Fukushima.

In Thompson et al. (2017), it is determined that people having an evacuation plan in hand are more likely to follow evacuation instructions: "Risk perception was a consistent positive predictor of evacuation, as were several demographic indicators, prior evacuation behavior, and having an evacuation plan."

In Alabdouli (2017), the case of an Orange County, California, tsunami is considered. If the case of an OC tsunami were to be considered here instead of a San Onofre nuclear power plant crisis, the evacuation instructions would change to: head east to any higher ground!
The rest of this paper is as follows...

- Section 2.1: The approximate driving distance algorithm

- Section 3: A case study

- Section 3.1: The evacuation planning of the case study

- Section 4: The results of the case study

- Section 5: Limitations and a discussion

- Section 6: Conclusions and future work

- Acknowledgments, references, and an appendix containing source code used in the case study

\section{MATERIALS AND METHODS}

\subsection{Approximate driving distance}

The following closely follows Riechel (2020c):

Each line of the input file has a longitude, latitude pair (in degrees) of an address. First, convert these from degrees to radians. Then compute the $x, y, z$ coordinates of each address:

$$
\begin{gathered}
x=\text { longitude } * r * \operatorname{Cos}\left(\phi_{0}\right) \\
y=\text { latitude } * r \\
z=\text { elevation }
\end{gathered}
$$

where $r$ is the radius of Earth, and $\phi_{0}$ is a centrally located latitude in the dataset. This forms an equirectangular projection (Hargitai et al., 2019).

Say $\left(x_{i}, y_{i}, z_{i}\right)$ is the coordinates of an address, and $\left(x_{j}, y_{j}, z_{j}\right)$ is the coordinates of a waypoint. The approximate driving distance between them is:

$$
\operatorname{distance}(i, j)=A b s\left(x_{i}-x_{j}\right)+A b s\left(y_{i}-y_{j}\right)+A b s\left(z_{i}-z_{j}\right)
$$

\footnotetext{
${ }^{*}$ Corresponding author
} 
This approximate distance, the Manhattan distance (Singh et al., 2013), is both a better approximation of the actual driving distance than the Euclidean distance and an order of magnitude faster to compute than it (Riechel, 2019, 2020a, 2020b). See Zeager and Stitz (2016) for a description of Euclidean distance.

The Manhattan distance is extremely fast to compute:

\begin{tabular}{|l|l|l|}
\hline & $\begin{array}{l}\text { Running time } \\
\text { of } 100 \text { million } \\
\text { calls } \\
\text { (milliseconds) }\end{array}$ & $\begin{array}{l}\text { Operations per } \\
\text { second }\end{array}$ \\
\hline $\begin{array}{l}\text { Manhattan distance, } \\
\text { aka "approximate } \\
\text { driving distance" }\end{array}$ & 296 & $337,837,838$ \\
\hline
\end{tabular}

Table 1. Execution speed of Manhattan distance, aka "approximate driving distance"

A pilot study was performed to determine how accurate Manhattan distances are to actual driving distances. In this nonrepresentative study of 200 green taxi cabs rides in New York City on January 1, 2016, starting at 12 AM EST, the following distribution was produced:

\section{Accuracy of Manhattan distance in NYC pilot study}

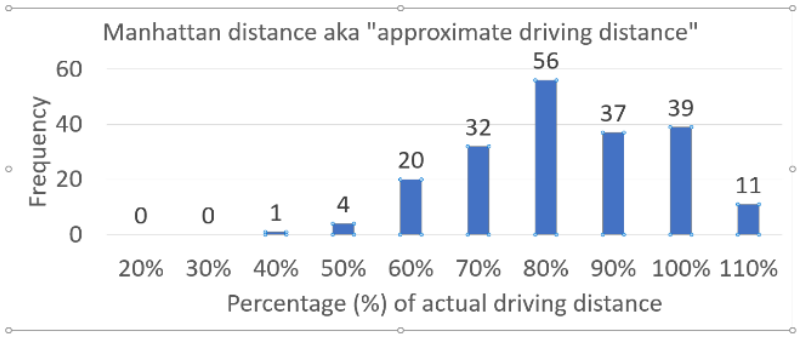

Graph 1. Accuracy of Manhattan distance in NYC pilot study

This distribution is confirmed as normal. On average, the Manhattan distance is about $80 \%$ of the actual driving distance, and the Manhattan sometimes overestimates actual driving distance.

There are many reasons why Manhattan distance might underestimate actual driving distance, including:

- $\quad$ Traffic controls (U-turns, one-way streets)

- Manmade obstacles (bridges)

- Natural obstacles (lakes, hills, mountains)

- Etc.

Also, the equirectangular projection tends to underestimate distance.

The approximate driving distance algorithm (Riechel, 2019, 2020a, 2020b) makes this evacuation planning possible. Using actual driving distances would take too long and be too expensive. The waypoint suggestions are just that: suggestions. In some cases, the approximate driving distance algorithm might not choose the closest waypoint.

\section{CASE STUDY}

In the following map, the San Onofre nuclear power plant is labeled " $R$ " for "reactor." The four waypoints out of Orange County, California, are labeled "W1," "W2," "W3," and "W4."
The four waypoints exit Orange County on the 405, 5, 57, and 91 freeways, respectively. Once a waypoint is reached, evacuees can travel in any direction, except back toward Orange County.

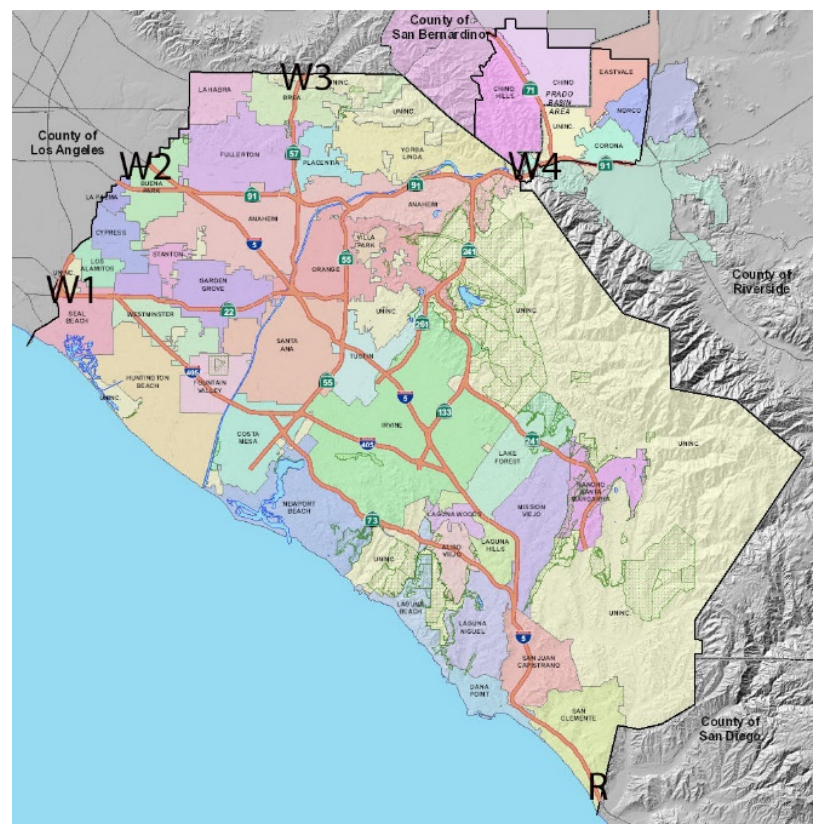

Map 1. The reactor and the four waypoints: map courtesy of Orange County, California

(https://www.ocgis.com/ocpw/landrecords/)

The following table gives more detailed information on the waypoints:

\begin{tabular}{|c|c|c|c|}
\hline Waypoint & Description & $\begin{array}{l}\text { Longitude } \\
\text { (degrees) }\end{array}$ & $\begin{array}{l}\text { Latitude } \\
\text { (degrees) }\end{array}$ \\
\hline$W 1$ & $\begin{array}{l}405 \text { on } \\
\text { LA/Orange } \\
\text { County } \\
\text { border }\end{array}$ & -118.0931346 & 33.7859273 \\
\hline$W 2$ & $\begin{array}{l}5 \text { on the } \\
\text { LA/Orange } \\
\text { County } \\
\text { border }\end{array}$ & -118.0114088 & 33.8748110 \\
\hline$W 3$ & $\begin{array}{l}57 \text { on the } \\
\text { LA/Orange } \\
\text { County } \\
\text { border }\end{array}$ & -117.8683537 & 33.946003 \\
\hline$W 4$ & $\begin{array}{l}91 \text { on } \\
\text { Riverside/Or } \\
\text { ange County } \\
\text { border }\end{array}$ & -117.6717187 & 33.8695321 \\
\hline
\end{tabular}

Table 2. The four waypoints

\subsection{Evacuation planning}

Each address is sent a color map of Orange County (much like Map 1 above), showing the nuclear reactor $\mathrm{R}$ and all four waypoints: W1, W2, W3, and W4.

For each address in Orange County (residential or business), the approximate driving distance algorithm is used to find the nearest waypoint. 
Along with the map, a suggested or recommended waypoint is given.

Residents do not have to follow the recommended waypoint. Instead, they can choose any of W1, W2, W3, or W4 in the event of a crisis at $\mathrm{R}$.

\section{RESULTS}

The following map shows the results of evacuating County of Orange, California, to the four waypoints:

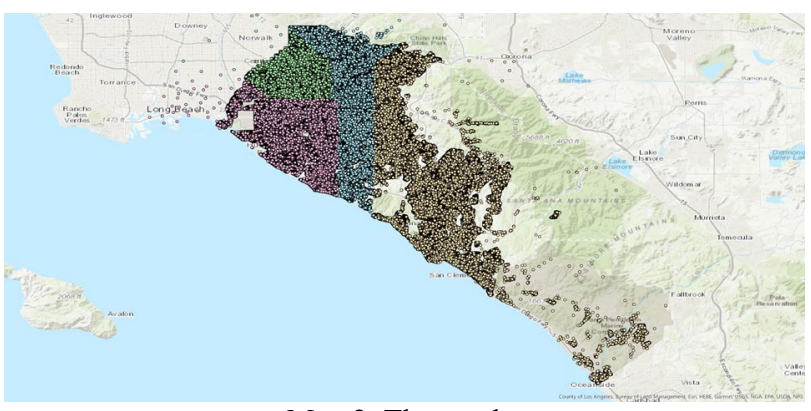

Map 2. The results

The addresses are color-coded to specify suggested evacuation waypoints:

\begin{tabular}{|l|l|}
\hline Color & Evacuation waypoint \\
\hline Purple & Evacuate by 405 freeway \\
\hline Green & Evacuate by 5 freeway \\
\hline Blue & Evacuate by 57 freeway \\
\hline Brown & Evacuate by 91 freeway \\
\hline
\end{tabular}

Table 3. Explanation of color codes in Map 2

The following table presents the number of addresses for each color code, and the total number of addresses:

\begin{tabular}{|l|l|}
\hline Waypoint & Count (addresses) \\
\hline W1 & 306,249 \\
\hline W2 & 129,219 \\
\hline W3 & 266,898 \\
\hline W4 & 445,429 \\
\hline TOTAL & $\mathbf{1 , 1 4 7 , 7 9 5}$ \\
\hline
\end{tabular}

Table 4 . The number of addresses routed to each waypoint, and the total number of addresses

\section{LIMITATIONS/DISCUSSION}

The presented software routed 1.1 to 1.2 million addresses in OC to the closest of four (4) waypoints in about eleven (11) seconds, because the approximate driving distance algorithm was used on a state-of-the-art laptop.
It is estimated that computing actual driving distances instead of approximate driving distances would take more than 53 days.

The main drawback of the approximate driving distance algorithm is its accuracy. On average, the approximate driving distance is about $80 \%$ of actual driving distances (Riechel, 2019, 2020a, 2020b).

Li et al. (2016) introduce the "six Vs" of Geospatial Big Data: volume, variety, velocity, veracity, visualization, and visibility. "In a world filled with Big Data, where the volume of data points to compute distances between, and the velocity at which these distances are expected to be computed, are both extremely high, a fast algorithm for computing approximate distances may be the only choice. This introduces the issue of veracity: How reliably accurate these approximate distances are" (Riechel, 2020c).

\section{CONCLUSION/FUTURE WORK}

Every evacuation scenario differs and requires custom software to solve.

The approximate driving distance algorithm might prove key to other evacuation problems, not just that of OC.

The approximate driving distance algorithm aids in the development and testing of evacuation software as it can be done quickly in real time.

For future work, the author would like to try solving more evacuation problems in the United States.

\section{ACKNOWLEDGMENTS}

Mike Vuong, GIS Supervisor, County of Orange, California, Fire Authority

Full Clinical Professor Brian N. Hilton and Professor Warren Roberts, Center for Information Systems \& Technology (CISAT), Claremont Graduate University (CGU)

\section{REFERENCES}

Alabdouli, K. (2017). Hypothetical tsunami scenarios and evacuation intention: A case study of Orange County, California. Journal of Geography and Natural Disasters, 7(3), 1-9. https://doi.org/10.4172/2167-0587.1000212

Hargitai, H., Willner, K., \& Hare, T. (2019). Fundamental Frameworks in Planetary Mapping: A Review. In H. Hargitai (Ed.), Planetary Cartography and GIS (pp. 75-101). Springer International Publishing. https://doi.org/10.1007/978-3-31962849-3 4

Li, S., Dragicevic, S., Castro, F. A., Sester, M., Winter, S., Coltekin, A., Pettit, C., Jiang, B., Haworth, J., Stein, A., \& Cheng, T. (2016). Geospatial big data handling theory and methods: A review and research challenges. ISPRS Journal of Photogrammetry and Remote Sensing, 115, 119-133. https://doi.org/10.1016/j.isprsiprs.2015.10.012

Ory, C., Leboulleux, S., Salvatore, D., Le Guen, B., De Vathaire, F., Chevillard, S., \& Schlumberger, M. (2020). Consequences of atmospheric contamination by radioiodine: The Chernobyl and Fukushima accidents. Endocrine. 
Riechel, J. (2019). A fast algorithm for computing approximate distances in the Cartesian plane. Proceedings of URISA GIS-Pro '19, New Orleans, LA. https://rive.google.com/file/d/126GnuqNw2V9dMUgIt8He4j9 5JXs0VoUQ/view?usp=sharing

Riechel, J. (2020a). Comparing Manhattan, Euclidean, and Actual Driving Distances. Proceedings of CalGIS 2020, Long Beach,

CA.

https://drive.google.com/file/d/1 wgjePJH6LXM6OAYHg-

PJkr2o-wVr8AK/view?usp=sharing

Riechel, J. (2020b). Extending Manhattan, Euclidean, and Actual Driving Distances into $3 D$. Unpublished. https://drive.google.com/file/d/16rkw9Ysn8BWfT7CpfvlnlaSw UgBw4Y4v/view?usp=sharing

Riechel, J. (2020c). Extremely Fast "Solution" to the LargeScale and Very Large-Scale Vehicle Routing Problem. Unpublished.

https://drive.google.com/file/d/1dq756Oua9iCrVG764ug7OVg $\underline{\mathrm{v} 5 \mathrm{BRFzBO} / \mathrm{view} \text { ? usp=sharing }}$

Singh, A., Yadav, A., Block, A. E., Rana, A., Block, E., \& Floor, G. (2013). K-means with Three Different Distance Metrics. International Journal of Computer Applications, 67(10), 13-17. https://doi.org/doi:10.5120/11430-6785

Thompson, R. R., Garfin, D. R., \& Silver, R. C. (2017). Evacuation from Natural Disasters: A Systematic Review of the Literature. Risk Analysis, 37(4), 812-839. https://doi.org/10.1111/risa.12654

Yanovskiy, M., Levi, O. N., Shaki, Y. Y., \& Socol, Y. (2020). Consequences of a large-scale nuclear accident and guidelines for evacuation: A cost-effectiveness analysis. International Journal of Radiation Biology, 96(11), 1,382-1,389. https://doi.org/10.1080/09553002.2020.1779962

Yoshimura, K., Saegusa, J., \& Sanada, Y. (2020). Initial decrease in the ambient dose equivalent rate after the Fukushima accident and its difference from Chernobyl. Scientific Reports, 10(1), 3,859. https://doi.org/10.1038/s41598-020-60847-0

Zeager, J., \& Stitz, C. (2016). College Algebra. http://dspace.calstate.edu/handle/10211.3/180387

\section{APPENDIX}

\section{A1. Source code file, 'main.cpp'}

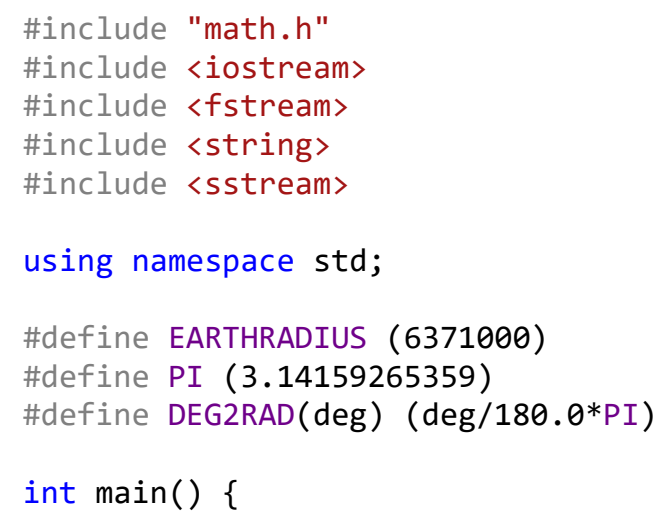

$$
\text { const int number_of_rows }=1147795 \text {; }
$$

// this is a two-pass algorithm. on the first pass, compute the average latitude:

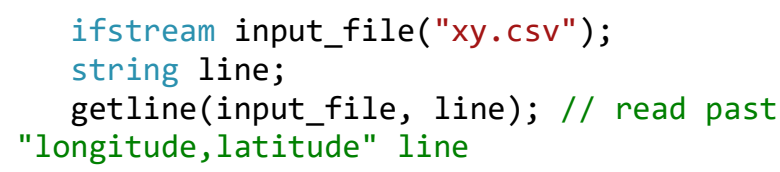




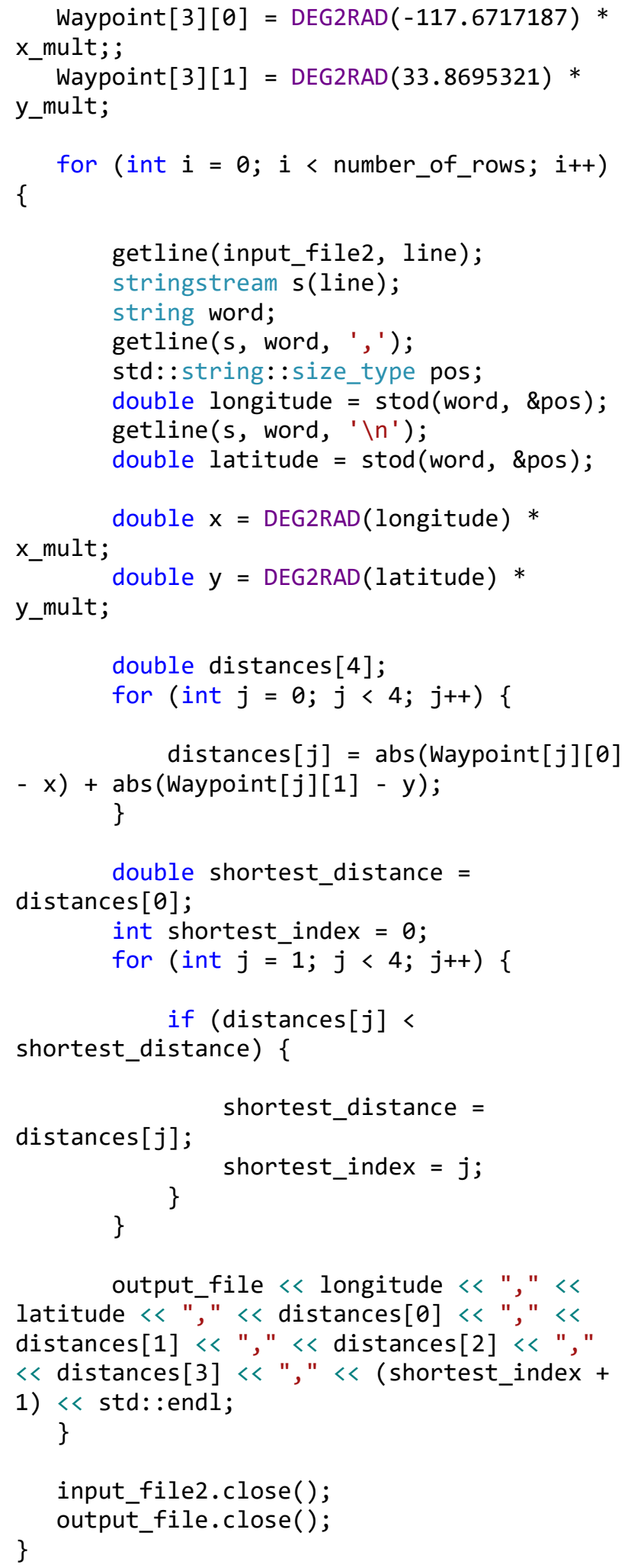

